\title{
INFCE brings international agreement on nuclear fuel cycle no nearer
}

\author{
THE International Nuclear Fuel Cycle Evaluation (INFCE) was \\ set up to release growing tension between states over control of \\ the nuclear fuel cycle and the possible spread of nuclear \\ weapons, but, argues Ian Smart, without political agreement \\ between governments INFCE alone could not do this
}

AFTER two and a half years of discussion INFCE has reached its public end with a final plenary session in Vienna. It was bred to be a dispassionate technical analysis of future fuel cycle options in the light of proliferation concerns. How well it has performed will now be tested. Assessments will inevitably vary, if only because different governments looked to INFCE to achieve different things. Especially at the outset, the United States, for example, looked for persuasive evidence that there would be sufficient newly-mined uranium to make reprocessing and the deployment of fast breeder reactors unnecessary for the foreseeable future, and that civil nuclear technology could be developed in 'proliferation-resistant' directions which avoided the presence of separated plutonium.

Others looked for some sort of contrary technical demonstration: that spent fuel would have to be reprocessed to reduce pressure on uranium supply or to make nuclear waste manageable; that plutonium could and should be used in existing thermal reactors; that fast breeder reactors would be needed as quickly as they could be developed; that there were technical means of making any of those activities resistant to proliferation. As the findings of INFCE are studied, it will be found that none of the participants got all it wanted. There is no firm agreement on the future availability of uranium, for example, nor therefore on the rate at which reprocessing should be undertaken or breeder reactors deployed. Indeed, about the only clear conclusions of the technical evaluation are that no conceivable fuel cycle could much reduce the possibility of proliferation and that no single pattern of technical evolution could be appropriate to all national circumstances.

But many of the 46 participating governments have learned something from it on the technical level, and now understand more about the difficulties of both nuclear

Ian Smart is an adviser on international energy affairs fuel cycles and proliferation. One part of INFCE's paradox, however, is that technical experts, dealing with issues many of which were essentially economic, contrived, above all, to achieve a political effect. What they demonstrated, in fact, was that the principal issues raised by a possible relationship between civil nuclear fuel cycles and the proliferation of nuclear weapons cannot be resolved by technical ingenuity or arbitrary government intervention, but only by political negotiation and political agreement.

INFCE can best be regarded as a course of drug therapy, administered to the fevered body of international nuclear energy relations. Partly by that means, the patient's temperature has been reduced. The pathology, however, remains unchanged. The prognosis must therefore be that, the drug having been withdrawn, the temperature will rise again unless the basic disease is identified and treated and the one thing INFCE has achieved in that connection is to establish that both diagnosis and cure must be political.

The one achievement of INFCE which may, perhaps, be forgotten in a flood of technical commentary is that, simply by meeting for more than two years, it has helped to dissipate the fierce antagonisms that have developed among nations in the nuclear fuel cycle trade.

INFCE arose from international turmoil. At the end of the 1960s, the NonProliferatin Treaty (NPT) expressed a new international consensus on the need to expand peaceful uses of nuclear energy

\section{'The temperature has been reduced . . . but the pathology remains unchanged'}

without increasing the number of countries controlling nuclear weapons. Provided countries without weapons - nonnuclear-weapon states - substantiated their renunciation of them by permitting international inspection, the treaty acknowledged their right to develop nuclear energy for peaceful purposes without further restriction. The NPT was never universally accepted, but, backed by the safeguards system of the International Atomic Energy Agency (IAEA) and supported by a large majority of governments, it offered some hope of setting the general standard for international behaviour. Five years later, however, both the standard and the hope lay wounded.

In 1974, India, which had not accepted the NPT, tested its first nuclear explosive. Almost simultaneously the Nixon Administration offered power reactors to Egypt and Israel, despite the fact that neither was a party to the NPT. Another nuclear-weapon state, France, having refused to sign the NPT, was negotiating sales of reprocessing technology to both Pakistan (which had also rejected the NPT) and South Korea. West Germany, agreed to provide yet another NPT non-party, Brazil, not only with reprocessing technology but also with equally 'sensitive' equipment for uranium enrichment. And meanwhile the oil crisis was exciting interest in nuclear power and persuading many of those committed to it to seek selfsufficiency.

Shocked by the Indian experience, and fearful that their commercial rivalry, if uncontrolled, might encourage a dangerous increase in the number of countries able to produce weapons, the major governments involved in nuclear exports formed the Nuclear Suppliers Group (NSG) and (secretly) agreed in 1975 on a set of guidelines to govern the export of 'sensitive' items. Although the suppliers eventually published these rules, in 1978, the fact that they had drawn them up in secret and without wider consultation aroused the resentment and apprehension of their customers, especially in the Third World. As to the substance of the NSG guidelines it was soon recognised that they went beyond the NPT itself, by calling for restrictions on the international transfers of certain allegedly 'sensitive' fuel cycle technologies such as enrichment and reprocessing, by limiting the use which those who did import such technology might make of it, and by recommending 
that exporters of nuclear fuel should retain the right to veto any reprocessing of it after use.

There was a widespread impression that the guidelines discriminated against the less developed nuclear countries, and that, by implying such countries had no general right to enrich uranium or reprocess spent fuel, even under safeguards, they made nonsense of a fundamental NPT concept. The NPT consensus had been founded on the idea that, for all non-nuclear-weapon parties, all peaceful and safeguarded nuclear activities were equally legitimate. Now it was said that some non-nuclearweapon states - and some peaceful technologies - were more equal than others.

These resentments were compounded in April 1977, with President Carter's announcement that the US would indefinitely defer reprocessing and the use of plutonium, and would also hold back development of fast reactors capable of 'breeding' plutonium. At the same time, it would withhold approval for foreign reprocessing of US-origin nuclear fuel. Such a policy, subsequently reinforced by the US Congress in the Nuclear NonProliferation Act, could be seen as a logical extension of the NSG guidelines. It now struck, however, not only at the transfer of reprocessing (or enrichment) technology but also at the conduct of reprocessing by those who already possessed the capacity: by Britain and France, which had plants, and by West Germany and Japan, which were seeking to build them. The effect was to divide the suppliers against themselves.

The overall result, by the spring of 1977 , was that commercial and political confidence in the whole field of international nuclear relations was at a nadir. Contracts had been suspended. Bilateral agreements had been unilaterally recalled, in mid-term, for renegotiation. Multilateral agreements, such as the NPT, had become playthings for minority interpretation. North-South nuclear relations were already embittered, and relations between developed countries were now becoming openly acrimonious. Some cooler review of proliferation issues was urgently needed, if rampant frictions were not to destroy the fabric of international cooperation and trade.

So INFCE was conceived at the the May 1977 Economic Summit in London, and officially born in October of that year in Washington. Its eight working groups,

\section{'Nothing less than the world pattern of nuclear energy development is at stake'}

\section{'As the findings of INFCE are studied, it will be found that none of the participants got all they wanted'}

with the Technical Co-ordinating Committee (TCC) composed of their $22 \mathrm{co}$ chairmen, have since held 70 meetings and produced 20,000 pages of commentaries and drafts. Now it is winding up, with a final plenary session whose task this week is to set its seal on the lengthy 'Overview' agreed in the TCC and on the even longer reports of the separate working groups. And next come the consequences of its three years' work.

In the short term, international nuclear relations will inevitably come under renewed pressure. In several countries Sweden and West Germany, for instance - the link between nuclear power and proliferation is an immediate issue in domestic politics. In several cases, as between the United States and Japan or the United States and Euratom, bilateral arrangements for nuclear cooperation and trade must now be re-cast in more restrictive form. And in August 1980, at the multilateral level, parties to the NPT must meet at their second Review Conference, where the political tensions unresolved by INFCE will again be prominent. Unless those and other immediate stresses are successfully absorbed, the temperature of international nuclear relations could easily be rising again by the end of the year.

Looking to the longer term, the problem is simpler but more difficult. What has collapsed since 1974 is not some set of formal rules or standards but rather the sense of international confidence: confidence that nuclear power can be used more widely without intolerably increasing the risk or fear of weapons proliferation; confidence that international contracts and agreements will be fulfilled, and that all those who seek the energy benefits of nuclear power will be able to draw equitably on international trade under safeguards.

As a result, nothing less than the world pattern of nuclear energy development is at stake. On one side, there is a model of development in which countries committed to nuclear energy programmes, but unconvinced that essential goods and services will always be available on acceptable terms, are driven to seek nuclear autarky as the only other route to energy security. With little regard to cost, more of them will then for instance, acquire their own plants for enrichment and reprocessing.
On the other side is a model of interdependent development, in which the same countries, offered a reliable system of nuclear trade and cooperation, will voluntarily optimise their programmes within a regional or global context. Political and economic rationality will then coincide to produce an efficient international distribution of labour in the nuclear fuel cycle, including its 'sensitive' stages.

The former pattern of 'fragmented autarky' would clearly generate greater fears of proliferation, while also being resistant to internationally agreed regulation or safeguarding. The paradox of some supplier policies since 1974, however, is that, by seeking to restrict nuclear trade and confine fuel cycle technology and capacity to a few countries in the name of non-proliferation, they have reduced the confidence of other states in inter-dependent development and actually increased the pressure on them to move to 'fragmented autarky', making the system progressively less amenable to international regulation.

The privately sponsored International Consultative Group on Nuclear Energy, in its recent report, has called for "a new 'bargain of confidence', in which credible guarantees of peaceful purpose will be balanced by firm assurances of access to nuclear services, materials and technology". Such a bargain of confidence can only be achieved by political negotiation. Non-proliferation treaties and international safeguards provide a starting point, and INFCE may offer some signposts. Experience of the last decade proves, however, that more is needed: some general code of conduct for international nuclear trade, agreed by importers as well as exporters, and possibly some more imaginative institutional arrangements for the international management of 'sensitive' activities and materials.

The alternative is not to be contemplated. Ten years ago, governments made the mistake of turning away from the NPT before its general provisions had been converted into concrete and equitable arrangements suited to specific international circumstances. INFCE has solved nothing, but it has bought an opportunity to repair some part of that gross error. If governments, especially in the advanced nuclear countries, fail to build onwards from INFCE into a lattice of political negotiation, design and agreement, they will have only themselves to blame if, in another few years, international nuclear relations are again as inflamed and painful as they were when it started.

In Nature next week Sir Hermann Bondi, chief scientist at the UK Department of Energy and leader of the UK delegation to INFCE over the past two years, explains how INFCE reached its technical conclusions. 